\title{
Las maestras de párvulos, en la historia de la educación en Chihuahua durante las primeras décadas del siglo XX
}

\author{
Martha Esther Larios Guzmán \\ Universidad Autónoma de Chihuahua \\ marthalarios guzman@yahoo.com.mx \\ Guillermo Hernández Orozco \\ Universidad Autónoma de Chihuahua \\ ghernand@uach.com
}

\section{Resumen}

A través del tiempo la mujer como profesional de la educación ha venido adquiriendo mayor presencia en la historia de la educación preescolar en Chihuahua. Por ello en el presente artículo se analiza la manera en que algunas de las mujeres, fueron asumiendo el papel de maestras para la atención de la primera infancia, selladas con mayor relevancia en la historiografía decimonónica al generalizarse su presencia como maestras reconocidas socialmente, hasta las primeras décadas del siglo XX, periodo en el que se crea la primera Escuela Normal de Educadoras en Chihuahua de la que egresan un gran número de señoritas que se desempeñan con calidad en su labor profesional y establecen las bases sólidas de la educación preescolar en el estado. El escrito se aborda a través de las siguientes categorías: panorama general del papel desempeñado por las mujeres chihuahuenses, desempeño de las educadoras chihuahuenses en el mercado laboral y el futuro de la carrera de educadoras en Chihuahua.

\section{Palabras claves \\ Maestras, primera infancia, Chihuahua.}

\section{Panorama general del papel desempeñado por las mujeres chihuahuenses}

En relación al papel de las mujeres, desde hace algunos años se ha visto la necesidad de analizar su situación desde un punto de vista histórico que permita reconocer las experiencias femeninas y los cambios en sus funciones, por lo que "es necesario identificar la posición de las mujeres en sus vidas, en su función social y en los estereotipos femeninos que definen el ser mujer" (Shorter, 1982: 24). El ser mujer es un elemento muy importante para su análisis, simplemente por el hecho de que sus roles han sido ignorados $y$ subestimados tanto a nivel nacional como mundial por mucho tiempo. Tal fue el caso de
México, Rusia, Francia, Alemania, Inglaterra, EUA, etc., en el que el ser femenino no tenía acceso a la individualidad ni a la ciudadanía, lo que implicaba un obstáculo para insertarse en el mercado del trabajo (Perrot, 1997: 140144).

De tal manera la incursión de la mujer y en especial en México, se fue configurando al servicio de la educación. En el caso de Chihuahua la primera maestra de la escuela para niñas de 1810, fue Eleuteria Carrasco, quien debía enseñar a las niñas la doctrina cristiana, a leer, escribir, hilar, tejer, coser y bordar, así como a ser dóciles y obedientes, posteriormente dando una instrucción similar incursionan Manuela Sáenz y María Guadalupe Terrazas. ${ }^{i}$ 


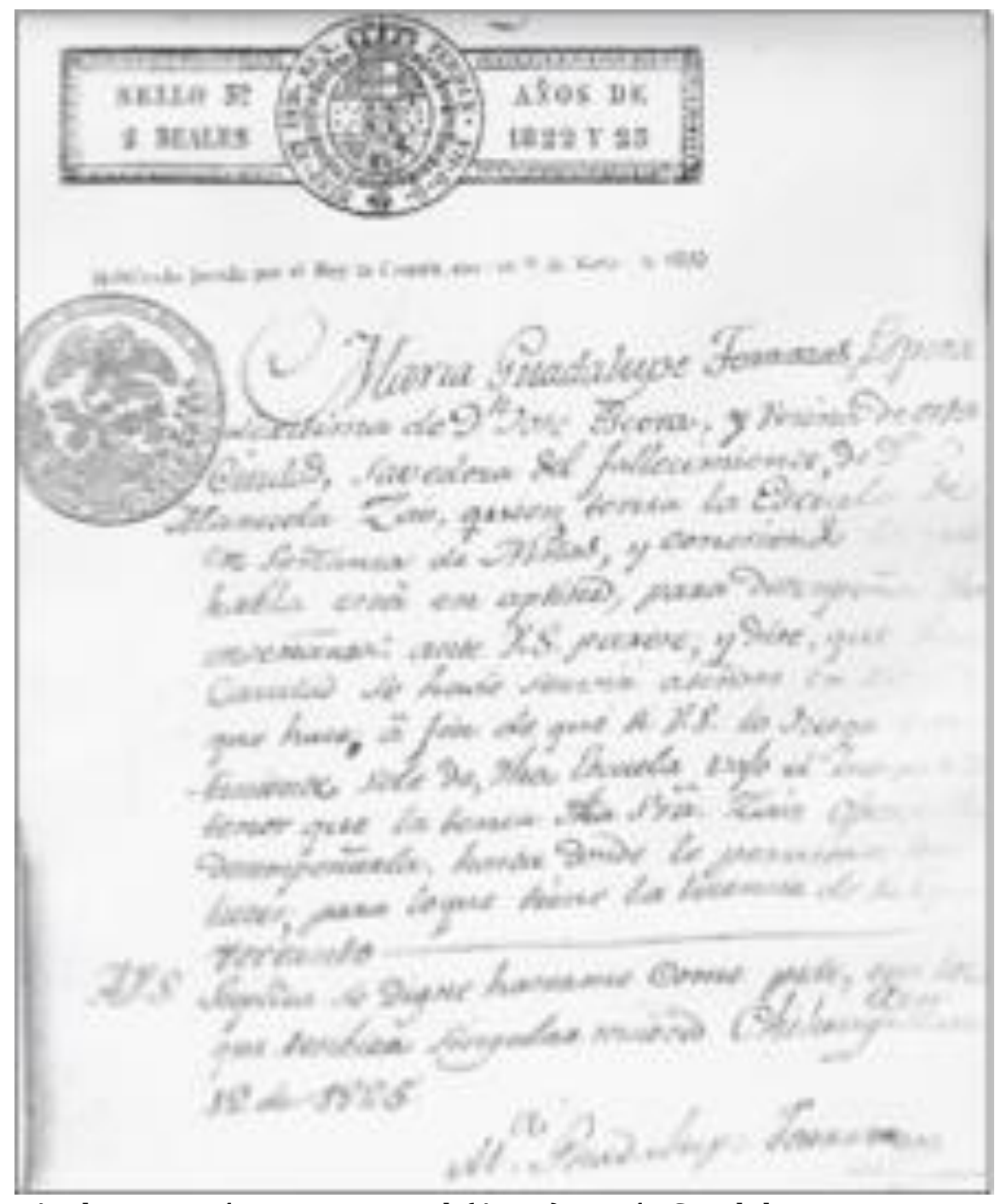

Archivo Histórico Municipal (AHM) María Guadalupe Terrazas.

Por su parte María Casimira Merino y Castillo y su hija Dominga Larrea, ofrecían su casa como escuela.ii En ella, la maestra Merino y Castillo, debía infundir a sus alumnos el temor de Dios y enseñar gratuitamente a las niñas pobres.

En el Estado se establecieron otras escuelas, entre la que figuró la escuela Lancasteriana. Es evidente que poco a poco se fue conformando la mujer, como la persona ideal para desempeñar el puesto de maestra, lo que dio un impulso importante a la feminización del magisterio. 


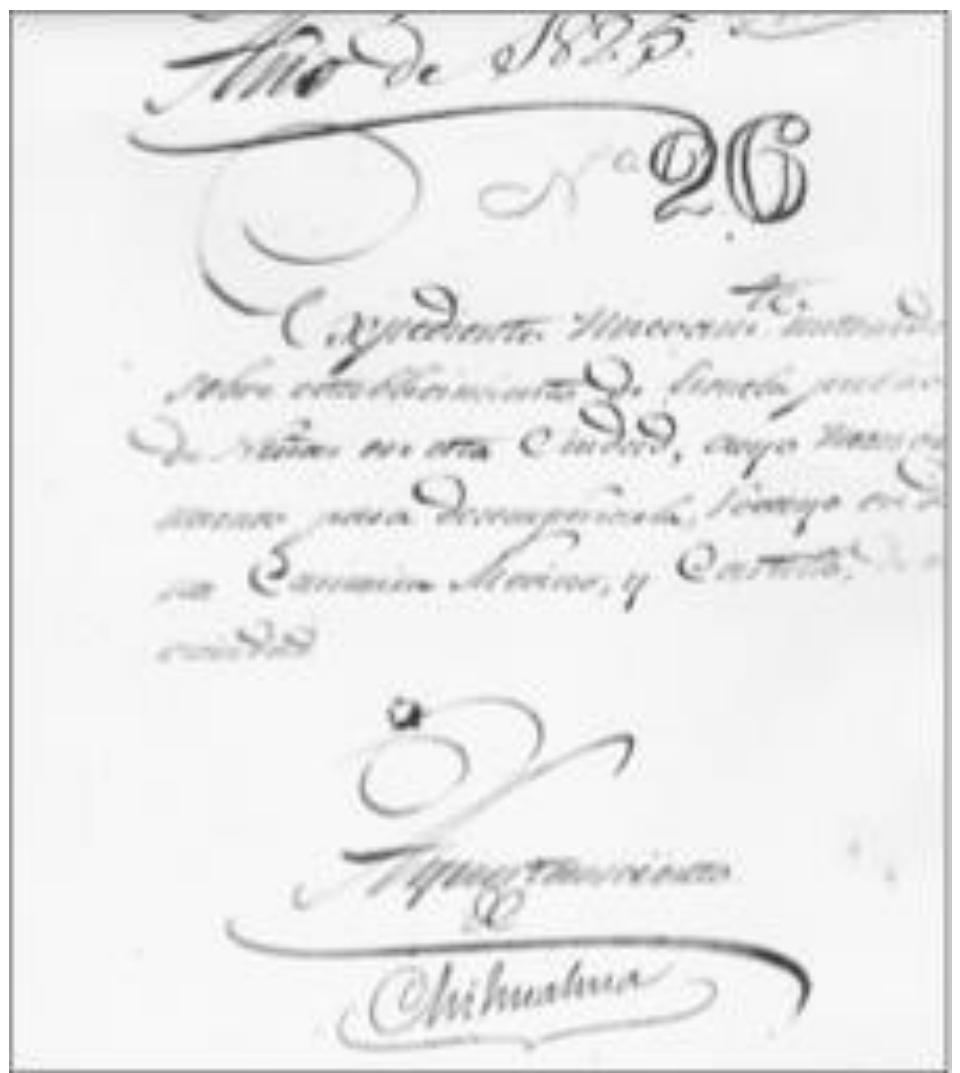

AHM. Documento que avala el puesto de María Casimira Merino y Castillo.

2. Desempeño de las educadoras chihuahuenses en el mercado laboral

A manera de resumen desde la óptica de (Larios, 2010: 29), es importante señalar que la educación preescolar vivió un proceso importante y trascendental en la educación de nuestro país, precedente que dio lugar a la creación de escuelas formadoras de especialistas para la atención de niños y niñas de 3 a 6 años.

La participación profesional de la mujer en el magisterio, específicamente en la educación preescolar a nivel mundial y nacional, prácticamente da inicio en siglo XIX, con los postulados de Enrique Pestalozzi y Federico Fröebel. En algunos estados de la República mexicana durante esta época, se habían creado algunas escuelas de párvulos tal es el caso: de San Luis Potosí, Guadalajara, Veracruz, Chihuahua, entre otros estados. Dentro de los cuales se destaca la ardua labor del eminente pedagogo Enrique Laubscher y
James Demarest Eaton estadunidense perteneciente a la Iglesia Congregacional quién funda la primera escuela de párvulos en Chihuahua.

La educación preescolar y la formación de educadoras de párvulos en México en su inicio, a principios del siglo XX tuvo una fuerte influencia de países del extranjero como: Alemania, Inglaterra, Italia y Estados Unidos. Las primeras maestras mexicanas interesadas en la educación preescolar salieron comisionadas por el gobierno mexicano a conocer los programas del kindergarten y de la formación de educadoras de párvulos, a su regreso realizaron una excelente reproducción de lo aprendido. Dicha formación fue parte del proyecto Porfirista por lo que las primeras educadoras mexiquenses eran señoritas de la clase alta que representaban el sector más culto de la sociedad, y que su propósito era formar maestras de párvulos además de reproducir 
su ideología y sus patrones de comportamiento.

Así la formación de "educadoras párvulas" inicia en el resto del mundo y en particular en Chihuahua - México, como una actividad exclusiva de las mujeres, ya que respondía a la naturaleza de la mujer: tierna, cariñosa, paciente, abnegada y con un saber intuitivo derivado del amor maternal; por lo que no se requería realizar arduos estudios para educar a los niños. Ser educadora significo más una cuestión de amor que de profesión, es decir, desempeñarse como una segunda madre.

En el caso de Chihuahua la creación de la Escuela Normal de Educadoras dentro del Instituto Científico y Literario (ICL) en 1929 dio un paso importante en la educación infantil ya que se contaría con especialistas para la atención de los pequeños párvulos.

Para desempeñarse como educadora se requería haber acreditado durante un periodo de dos años, todas y cada una de las materias establecidas en el mapa curricular y solicitar ante la dirección del ICL el título que les acreditara como maestras de jardín de niños.

El fruto de la Escuela Normal de Educadoras se dio en 1932, fecha en que recibieron el título de maestras de jardines de niños, 28 de las 75 alumnas inscritas en esta escuela. Al respecto, Carmen Gutiérrez alumna de esta generación comenta: "el 20 de noviembre de 1932, siendo Gobernador del Estado el General Rodrigo M. Quevedo, se nos hizo entrega de los títulos correspondientes a la Carrera de Educadoras, en el escenario del desaparecido Teatro de los Héroes".iii

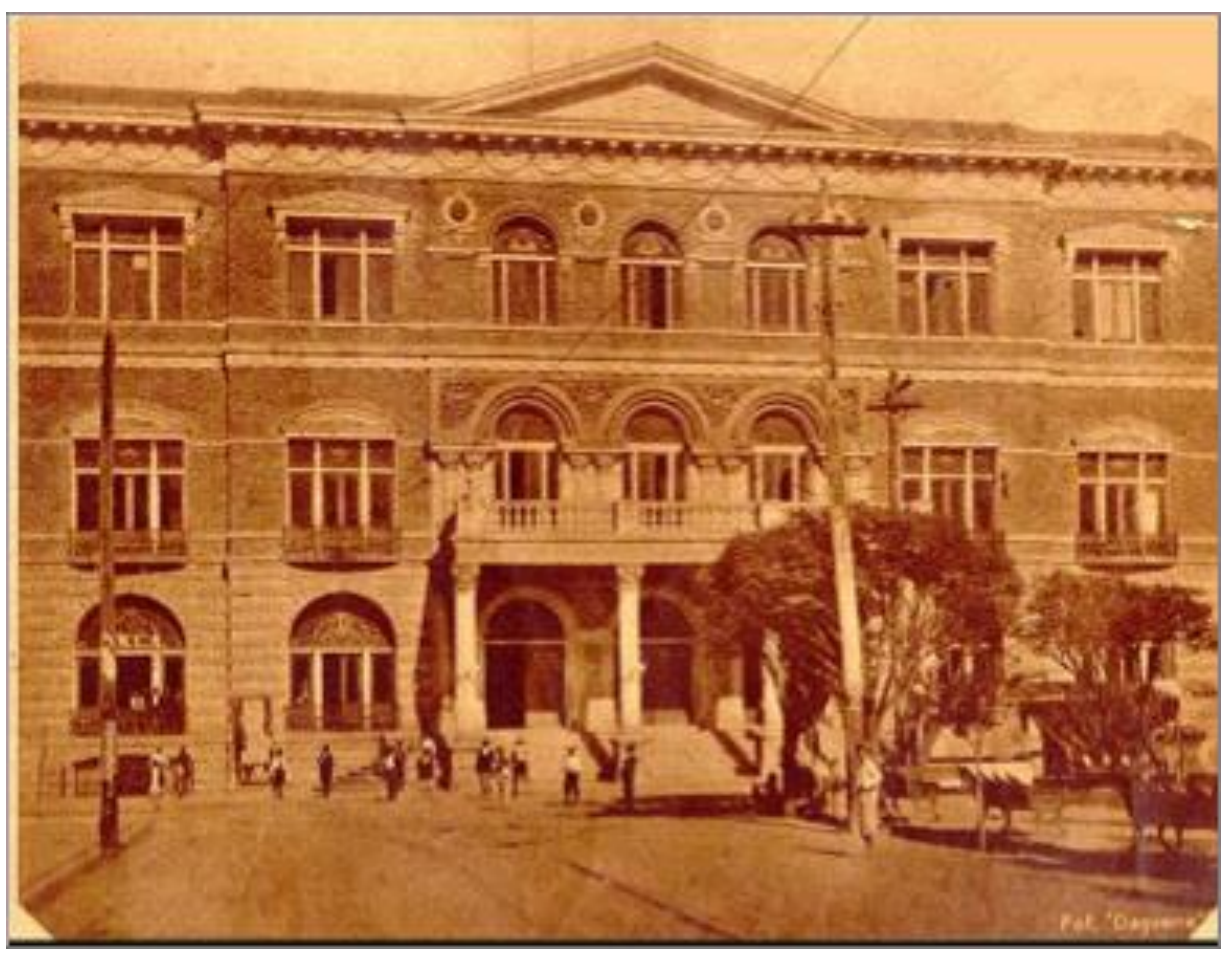

Archivo Histórico de la Universidad Autónoma de Chihuahua (AHUACH). Antiguo Teatro de los Héroes.

De tal forma las egresadas de la primera Escuela de Educadoras fueron interiorizando y construyendo la realidad y racionalidad de su vida profesional; crearon una identidad propia como profesionistas encargadas de dar educación a niños pequeños. Esto, como producto de los calificativos que se les heredó y de las interacciones como: profesoras 
disciplinadas, amorosas, responsables, con valores y normas que les demandó el contexto social durante el periodo en que les permitió desempeñarse; con amplia cultura general y conocimiento sobre los niños pequeños, a quienes debían prodigar toda clase de atenciones; ser además dinámicas, gozar de buena salud, ser creativas e inminentemente laboriosas; todo esto, aunado al firme propósito de brindar una atención adecuada a los pequeños y atender los requerimientos educativos que se les exigían.

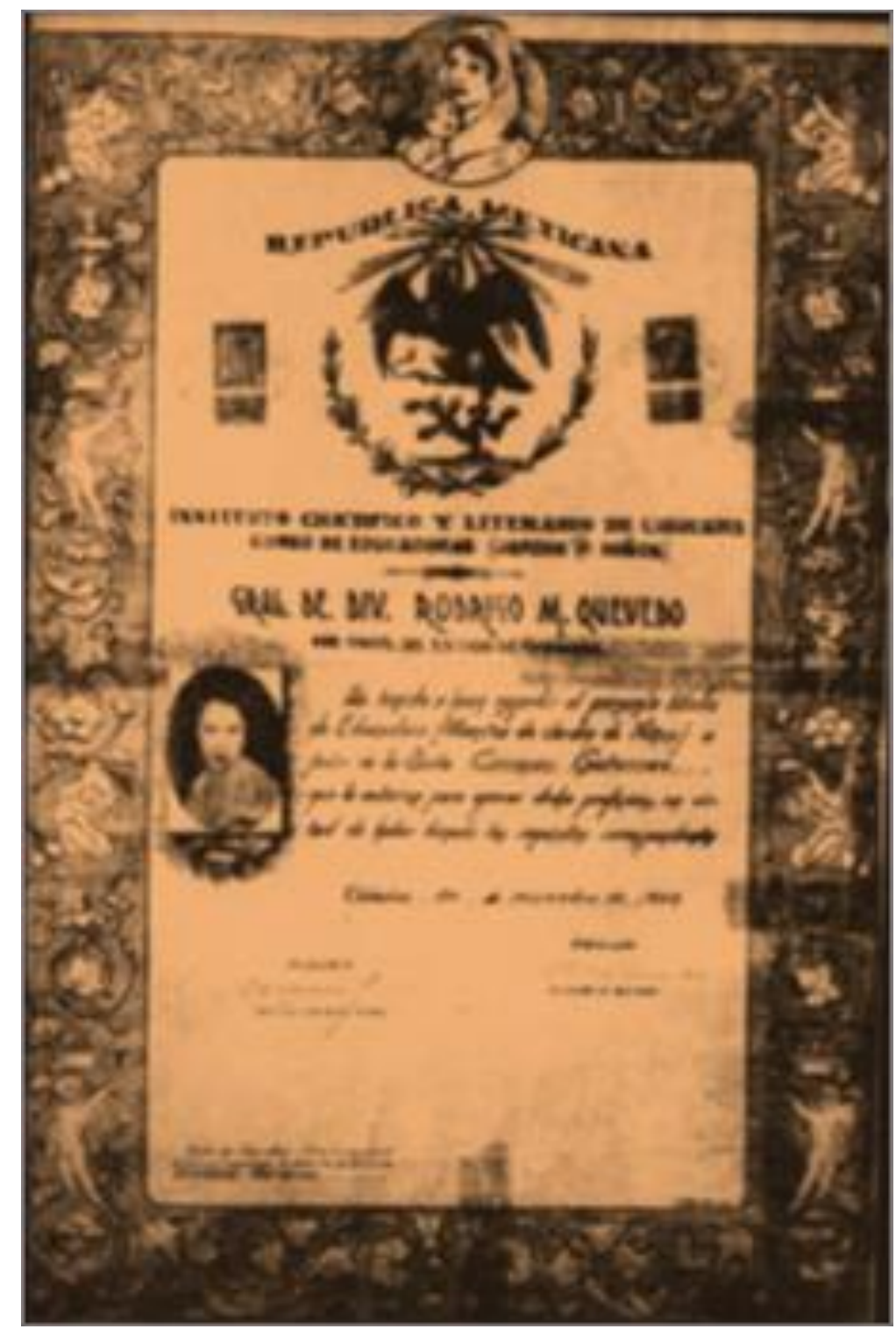

Título de Educadora de la señorita Carmen Gutiérrez. AHUACH 1932.

El desempeñar la función de maestra significaba no sólo socializar la formación escolar y laboral, sino el ir formando imágenes sobre el trabajo docente desde muy temprana edad. En el acontecer de las escuelas, los docentes estaban influidos por varias circunstancias: el trabajo concreto de cada maestro que fungía como compañero, las restricciones en cuanto a espacio, tiempo y recursos, las formas de organizarse, las prácticas cotidianas, además de las presiones y exigencias que imponían padres de familia y 
autoridades.

Para (Zapata, 1952: 17), el ideal del trabajo en preescolar se sustentaba en que debía ser una institución que proporcionara a los alumnos un ambiente lo más parecido al hogar, sencillo, limpio, ordenado, en el que imperaran la unión y la confraternidad. Donde el niño se moviera con toda libertad bajo la observación cuidadosa y activa de la educadora, quien no debía perder detalle sobre la actuación de aquél, con el fin de conocerlo y guiarlo mejor. Sin duda estos supuestos hicieron que tanto la sociedad como las educadoras mismas se forjaran una actitud maternal, como un "deber ser".

\subsection{Las educadoras en el ejercicio de su función} De 1931 a 1935 se crearon diferentes Jardines de Niños en el estado de Chihuahua; las educadoras egresadas del Instituto Científico y Literario fueron las encargadas de fundar estos jardines "apoyadas generalmente por maestras empíricas (SEECH, 2000: 32). De esta manera, el mercado laboral daba apertura a todas las egresadas de la Escuela de Educadoras, estableciéndose diversos Jardines de Niños en la entidad, anexos a las escuelas primarias, en los que prestarían sus servicios.

Aurelia Agüero se estableció como directora del jardín de niños del Parque Lerdo de Tejada, con un sueldo de $\$ 100.00 \mathrm{y}$, como auxiliares, Josefina Balderrama, Margarita Valdés y Soledad Gallegos, con un sueldo de $\$ 50.00$ mensuales. También se destacaron las siguientes educadoras fundando los siguientes planteles escolares.

\begin{tabular}{lll}
\hline Fecha & Jardín de niños & Maestra \\
\hline 1931 & Independencia & Margarita Bernal \\
& Anexo a la Escuela 138 & Concepción Morales \\
& Anexo a la Escuela Federal Tipo & Elena Meléndez \\
& Praxedis G. Guerrero & Eva González \\
Anexo a la Escuela 225 & Carmen Gutiérrez Pérez \\
Anexo a la Escuela Centenario & Beatriz González \\
Escuela 139 & Hermelinda Delgado \\
& Escuela Melchor Guaspe & Esther Ávila \\
Escuela Modelo & Ana María Olmos \\
Escuela Ponce de León & Eva Pérez Garza \\
Fundación de Ávalos & Sara Meléndez \\
Escuela Artículo 123 & Herminia Payán \\
\hline
\end{tabular}

Después de algunos años, los jardines de niños que funcionaron en anexos se fueron separando para integrarse en sus propios edificios. 


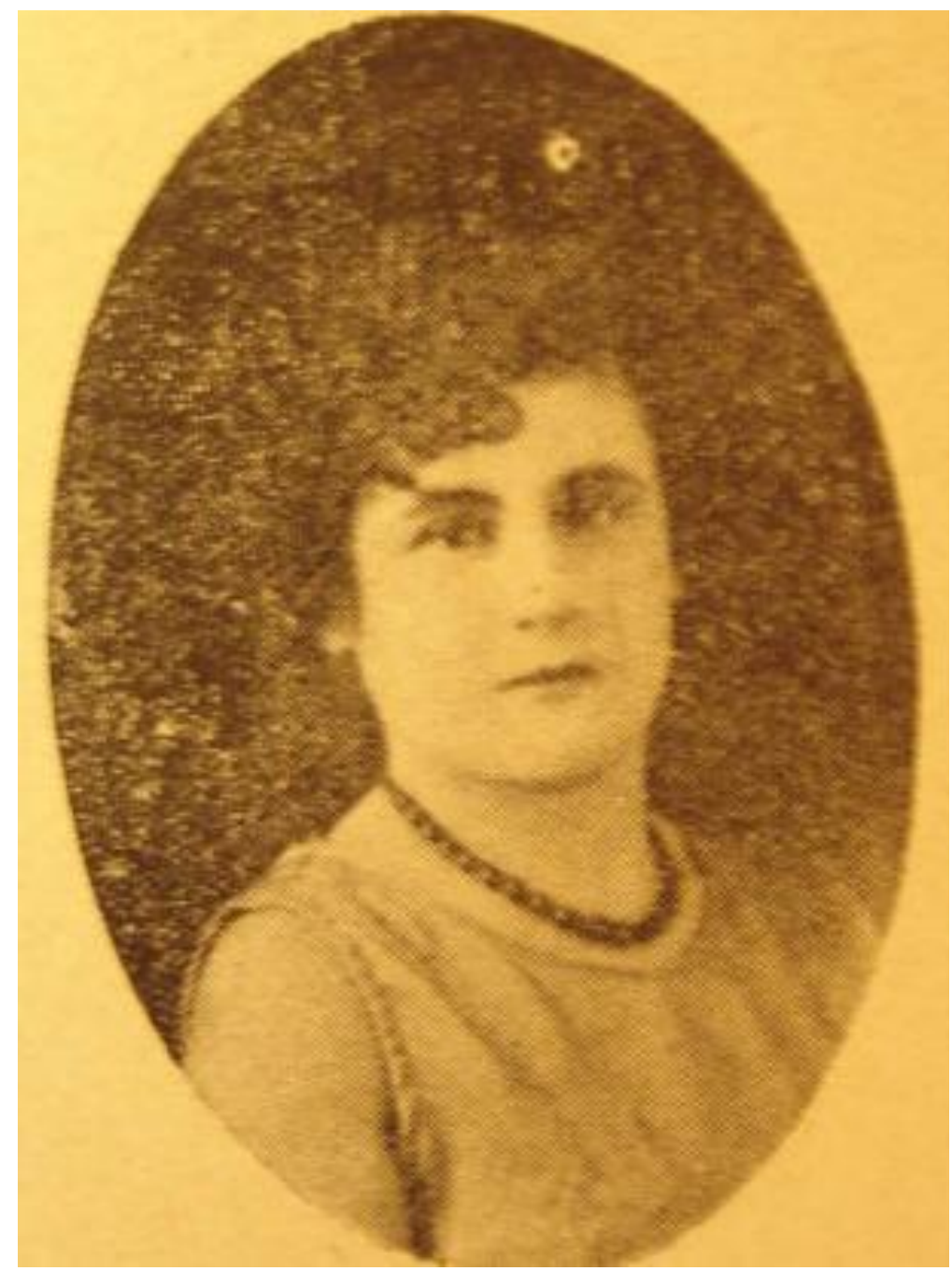

Aurelia Agüero Esquivel. Archivo Histórico de la UACH.

Es así como las egresadas de la primera escuela de educadoras incursionan en el mercado laboral en beneficio de la niñez chihuahuense. Tal como lo confirma (Palma, 1988:9), este semillero de entusiastas educadoras fructificó, ya que de inmediato empezaron a abrir jardines de niños en el año 1931, organizando a la vez la sociedad de educadoras; en este tiempo era Director General de Educación el profesor José A. Espejo.

El panorama general de la educación preescolar de 1930-1932 fue favorable, durante la presidencia de Pascual Ortiz Rubio la acción educativa se volvió radical, lográndose de una vez por toda la eliminación de la influencia religiosa en la educación impartida por el Estado.

Podía verse también cómo los niños egresados de este nivel educativo eran bien aceptados en las primarias por su buena preparación.

La preparación profesional de las educadoras les permitía responder con responsabilidad en el trabajo. Las autoridades educativas organizaban cursos a los que acudían educadoras de todo el país, y de ellos surgieron grandes aportaciones de música, cuentos, rimas y leyendas para niños. Todo esto con la finalidad de que los niños contaran con elementos de cultura mexicana. 


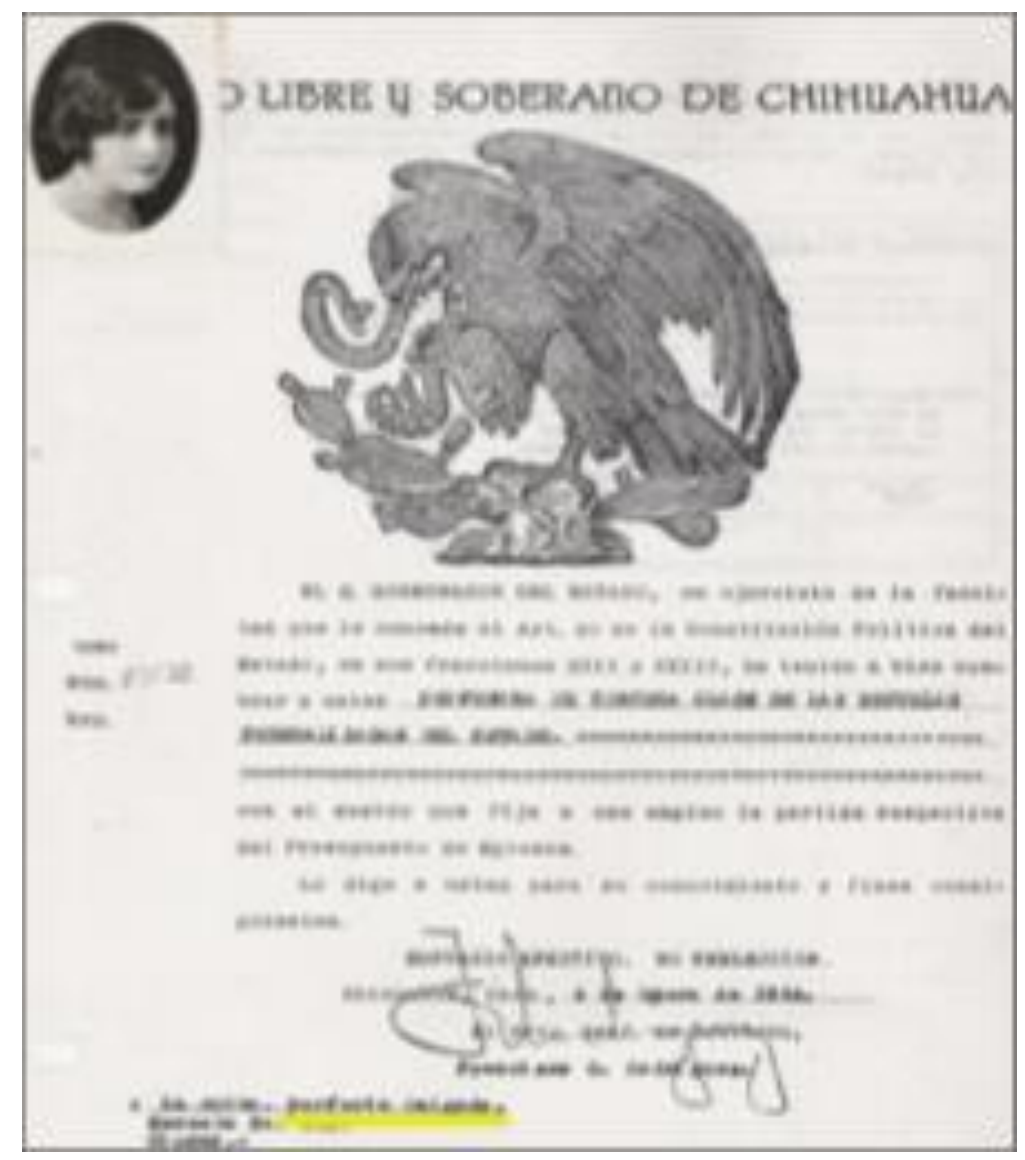

Nombramiento de la Srita. Perfecta Delgado. AHUACH.

De 1932 a 1940 se siguieron otorgando diversas plazas, como fue el caso de la señora María M. Vda. de Amaya, a quien se le nombró profesora de cuarta clase de las escuelas oficiales del estado el 4 de enero de 1934; a la señorita Carmen Marmolejo, el 13 de abril de 1936 se le designó como maestra rural clase "C" de las escuelas federalizadas del estado; a la maestra Eva González en diciembre de 1938 se le nombró maestra rural clase "A"; a la señorita Herminia Payán, en febrero de 1934 se le nombró profesora de segunda clase. En el mismo año, a la señora Meléndez se le otorgó nombramiento como profesora de cuarta clase; el 4 de enero de 1934 a Perfecta Delgado, como profesora de tercera clase. El 10 de enero de 1938 se nombró a la profesora Aurelia Agüero Esquivel como primera inspectora de los jardines de niños.
Durante este año se formó también la sección de jardines de niños, que se encargaría de controlar y orientar a las educadoras de la entidad. Dicha sección estuvo integrada por las siguientes profesoras:

En el área técnica: Aurelia Agüero Esquivel En el área administrativa: Carmen Meza de Hernández En el área musical: Margarita H. de Campos Posteriormente, el puesto de Inspectora de jardines de niños fue otorgado a la maestra Carmen Meza de Hernández, quien siguió con el ánimo de capacitar e impulsar a las educadoras a su cargo en base a la pedagogía de la escuela nueva, "método natural".

Como puede observarse, para estas fechas, aún había movilidad laboral para las egresadas de la primera escuela de educadoras. 


\section{El futuro de la carrera de educadoras en Chihuahua}

La legislación vigente y los convenios y acuerdos internacionales en que México ha participado representan una situación privilegiada para la mujer mexicana, al menos en términos institucionales. Sin embargo, para que los derechos de las mujeres sean reconocidos y respetados como una realidad en un estado democrático, no es suficiente lo escrito y manifiesto. Había que hacer presente todo lo anterior en la cotidianeidad, lograr la participación con igualdad de oportunidades de todos y de todas en el contexto social, económico y político del Estado mexicano; contar con soporte legal eficiente en la atención, apoyo y orientación de las mujeres para cuando ellas requirieran de estos servicios.

Aunque las políticas federales para la formación de docentes son predominantes desde 1921, las necesidades estatales y la participación de personas y grupos locales tienen un papel significativo en la recepción y adaptación de las políticas así como en el cierre y apertura de las instituciones escolares como fue el caso de la Escuela Normal de Educadoras en Chihuahua quien dio apertura y clausura en varias ocasiones: 1929 dentro del Instituto Científico y Literario, 1945 en la Escuela Normal del Estado, 1965 escuela particular de la maestra Josefina Seáñez de Avitia, 1968 en el Instituto Pedagógico Chihuahuense y finalmente, en 1977 se establece para quedarse dentro de la Escuela Normal del Estado Luis Urías Belderráin.

\section{A manera de reflexión}

La Escuela Normal de Educadoras como institución educativa estuvo entretejida por las historias, sentimientos y pensamientos personales: el género, la clase social, la ideología, la conciencia social. Estos factores delinearon el presente y el futuro de la actuación de las educadoras. Para Perrot y Duby, la historia de las mujeres no defiende tesis alguna sobre el progreso o el retroceso de la condición femenina en los diversos periodos históricos, sino que opta por ilustrar la diversidad de condiciones sociales, creencias religiosas, tradiciones culturales y trayectorias individuales de las mujeres, y mostrar que ni la condición femenina ni la masculina tienen una esencia que las defina, sino que son construcciones históricas estrechamente relacionadas entre sí y cuya lógica resulta imposible desentrañar.

Las egresadas de la Escuela Normal de Educadoras se formaron como educadoras reconocidas socialmente, trabajando al servicio del pueblo. Su papel docente resultó favorecido con la fundación de diversos jardines de niños en el estado de Chihuahua y con su participación en eventos políticos y sindicales. Lo anterior lo corroboran los casos de Carmen Meza, quien contribuyó en los congresos coordinados por la Sección 8a. del SNTE; de Aurelia Agüero, la cual ostentó puestos educativos de relevancia -supervisora de los jardines de niños del estado, profesora en la Escuela Normal del Estado- y dio apertura en 1929 al primer jardín de niños que serviría para que las estudiantes de dicha escuela realizaran sus prácticas, y Cruz Valderrama, catedrática en el instituto Científico y Literario durante el periodo 1943-1954. Cada una de las egresadas se desempeñó, brindando sus servicios en los diferentes planteles de educación infantil. Asumieron el legado recibido a nivel nacional de prestigiadas educadoras: Rosaura Zapata, Berta Von Glumer, Estefanía Castañeda y Dolores Correa Zapata, entre otras, quienes participaron en la política educativa del momento y que gracias a su preparación se les permitió opinar y legar su pensamiento, incluso para generaciones que vivieron durante los años posrevolucionarios. Todo esto las llevó a pasar de ser maestras "sin poder" e "invisibles", a hacerse visibles y empezar a 
obtener cierto poder y reconocimiento.

\section{Referencias}

Bastián, Jean Pierre, (1993) Los disidentes. Sociedades protestantes y revolución en México, 1872-1911. El Colegio de México. Impresora y Encuadernadora Progreso, S.A de C.V. México, D.F.

Larios Guzmán, Martha Esther, (2009). Historia de la educación preescolar en Chihuahua 1885- 1940. Asociación Universitaria Comunicación y Cultura. Gobierno del Estado de Chihuahua. Chihuahua, México.

Larios Guzmán, Martha Esther y Guillermo Hernández Orozco, (2008), La universalización de la educación superior Escuela Normal de Educadoras en Chihuahua, México. Universidad 2008, 6to. Congreso Internacional de Educación Superior, Palacio de las Convenciones, La Habana, Cuba.

Secretaría de Educación Pública, (1982), Evolución histórica de la educación preescolar. México D.F.

Shorter, Edward, (1982) A history of woman 's bodies. Londres, Penguin. Zapata, Rosaura, (1952) Teoría y práctica del jardín de niños, segunda edición, México, D.F.

\footnotetext{
${ }^{\mathrm{i}}$ Archivo Municipal de Chihuahua (AHM), Fondo Colonial, caja 46, exp. 5, documento con fecha 12 de marzo de 1825.

ii AHM Fondo Independencia, sección Secretaría, caja 1, expediente 16, documento de 1825.

iii Palabras textuales de la maestra Carmen Gutiérrez, egresada de la primera generación de la Escuela de Educadoras en Chihuahua 1929. Boletín de la Sociedad Chihuahuense de Estudios Históricos. Marzo de 1987.
} 